January 2012

\title{
Aqueous-methanolic extract of sweet flag (Acorus calamus) possesses cardiac depressant and endothelial-derived hyperpolarizing factor- mediated coronary vasodilator effects.
}

Abdul Jabbar Shah

Aga Khan University

Anwar Gilani

Aga Khan University

Follow this and additional works at: http://ecommons.aku.edu/pakistan_fhs_mc_bbs

Part of the Natural Products Chemistry and Pharmacognosy Commons

\section{Recommended Citation}

Shah, A., Gilani, A. (2012). Aqueous-methanolic extract of sweet flag (Acorus calamus) possesses cardiac depressant and endothelialderived hyperpolarizing factor-mediated coronary vasodilator effects.. Journal of Natural Medicines, 66(1), 119-126.

Available at: http://ecommons.aku.edu/pakistan_fhs_mc_bbs/39 


\title{
Aqueous-methanolic extract of sweet flag (Acorus calamus) possesses cardiac depressant and endothelial-derived hyperpolarizing factor-mediated coronary vasodilator effects
}

\author{
Abdul Jabbar Shah • Anwarul Hassan Gilani
}

Received: 13 January 2011/Accepted: 14 June 2011/Published online: 9 August 2011

(C) The Japanese Society of Pharmacognosy and Springer 2011

\begin{abstract}
This investigation was aimed to probe the pharmacological base of medicinal use of Acorus calamus in ischemic heart diseases. Effect on heart parameters was studied in isolated rabbit heart while coronary vasodilator effect was studied in isolated bovine coronary arterial rings, suspended in tissue baths filled with Krebs solution, maintained at $37^{\circ} \mathrm{C}$, aerated with carbogen and responses were measured on PowerLab data acquisition system. In Langendorrf's perfused rabbit heart, the crude extract of Acorus calamus (Ac.Cr) at $0.01-10 \mathrm{mg} / \mathrm{mL}$ partially suppressed force of ventricular contractions (FVC), heart rate (HR) and coronary flow (CF). The ethylacetate fraction completely suppressed FVC, partially suppressed HR and $\mathrm{CF}$, while the $n \mathrm{Hexane}$ fraction exhibited similar effect on FVC and HR but increased CF, similar to methacholine and arachidonic acid. In bovine coronary arterial preparations, Ac.Cr caused inhibition of U46619 (20 nM)-precontractions, which was blocked in presence of increasing concentration of $\mathrm{K}^{+}(4.8-20 \mathrm{mM})$, tetraethylammonium $(1 \mu \mathrm{M})$ and SKF525A $(10 \mu \mathrm{M})$, similar to arachidonic acid and methacholine, indicating $\mathrm{K}^{+}$channels activation and possible involvement of endothelial-derived hyperpolarizing factor (EDHF). Activity-directed fractionation revealed that EDHF-mediated activity is concentrated in the $n \mathrm{Hex}-$ ane fraction. When tested against high $\mathrm{K}^{+}$, the ethylacetate fraction was found more potent than parent crude extract
\end{abstract}

A. J. Shah · A. H. Gilani ( $₫)$

Natural Products Research Division, Department of Biological and Biomedical Sciences, Aga Khan University Medical

College, Karachi 74800, Pakistan

e-mail: anwar.gilani@aku.edu

A. J. Shah

Department of Pharmacy, COMSATS, Institute of Information Technology, Abbottabad 22060, Pakistan and $n$ Hexane fraction. These data indicate that Ac.Cr mediates coronary vasodilator effect primarily through EDHF, responsible for the increase in CF, while the cardiac depressant effects may be due to the presence of additional cardiac depressant constituent(s), thus provides possible mechanistic basis to its medicinal use in ischemic heart diseases.

Keywords Acorus calamus $\cdot \mathrm{EDHF} \cdot \mathrm{K}^{+}$channels . Cardio-suppressant $\cdot$ Coronary dilator

\section{Introduction}

Acorus calamus L. (Araceae), commonly known as "Sweet flag", has been known since 2000 years, Ibn Sina called it waj and Dioskurides akopov. A description of the plant exists in the Theatrum Botanicum of J. Parkinson (1640) and it has been listed since then in a number of Pharmacopoeia and Codices, like British Pharmaceutical Codex, 1934 [1]. The plant was established in England as a wild plant, commonly found in moist habitats throughout North America, Europe and Central Asia. It has been taken over the centuries as a remedy to treat various ailments [2]. The roots and rhizomes of this plant have been used in the Ayurvedic medicine, as well in this part of the world for cardiovascular disorders, such as, ischemic heart diseases [3].

Phytochemistry of the plant revealed the presence of glucoside, alkaloid and essential oil containing calamen, calamenol, calameon, asarone and sesquiterpenes [4]. It is also known to contain a better glycoside named acorine along with eugenol, pinene and camphene [5].

The plant is reported in the past for many biological activities, including, antimicrobial [6], antidiarrhoeal [7], 
dyslipidemic [8], neuroprotective [9], antioxidant [10], anticholinesterase [11], wound healing [12] and we reported as spasmolytic [13] hypotensive and vascular modulator [14]. As an extension of our previous work [14], this investigation was undertaken to study the mechanism(s) responsible for the medicinal use of Acorus calamus in ischemic heart diseases by using isolated rabbit heart and bovine coronary artery. We have determined the functional nature of the coronary vascular relaxation being of endothelial origin and mediated through the endothelialderived hyperpolarizing factor (EDHF).

\section{Materials and methods}

Plant materials

Rhizomes of Acorus calamus (3.12 kg) were collected in Swat District, KhyberPukhtonkhwa (formally, N.W.F.P.), Pakistan in November 2004 and authenticated by Assistant Professor Mr. Mehboob-ur-Rehman at the Department of Botany, Govt. PG Jehanzeb College Saidu Sharif Swat, Pakistan. A voucher specimen (A 200) was deposited at the herbarium of the same Department.

\section{Preparation of crude extract and fractionation}

The powdered material about $1.70 \mathrm{~kg}$ was soaked in $70 \%$ aqueous-methanol for 3 days with occasional shaking. It was then filtered through a muslin cloth and then through a Whatman qualitative grade 1 filter paper. This procedure was repeated thrice and the combined filtrate was evaporated on rotary evaporator at $35-40^{\circ} \mathrm{C}$ under reduced pressure $(-760 \mathrm{mmHg})$ to a thick, semi-solid mass of dark brown color; i.e. the crude extract (Ac.Cr), yielding approximately $10 \%$.

Activity-directed fractionation of the crude extract was carried out by standard phytochemical procedures, using different organic solvents [15-17]. A known quantity of the extract $(49.44 \mathrm{~g})$ was dissolved in $100 \mathrm{~mL}$ of distilled water. This was transferred to a separating funnel. $n$ Hexane $(50-70 \mathrm{~mL})$ was then added. The mixture was shaken vigorously with regular allowing the air to escape out. It was kept for about $30 \mathrm{~min}$ to let the two layers separate. The upper layer of $n$ Hexane was acquired and the same procedure was repeated twice more and all the $n$ Hexane layers were collected and concentrated in a rotary evaporator to obtain the $n \mathrm{Hex}$ ane fraction (23.6\%). Similarly, ethylacetate fraction (30\%) was also obtained.

Ac.Cr and its fractions were solubilized in distilled water and $10 \%$ dimethyl sulfoxide (DMSO), respectively, for use in the in vitro experiments.
Drugs and standards

The following reference chemicals were obtained from the sources specified: arachidonic acid, methacholine chloride, 9-11-dideoxy-9 $\alpha, 11 \alpha$ methanoepoxyprostaglandin $\mathrm{F}_{2 \alpha}$ solution (U46619), tetraethylammonium (TEA) bromide, and SKF525A hydrochloride (Wako Chemicals, Japan). Heparin from Leo Pharmaceutical Products, Denmark. Verapamil hydrochloride, glibenclamide, indomethacin, $N \omega$-nitro-L-arginine methyl ester (L-NAME) and DMSO from Sigma Chemical Company, USA. All chemicals used were of the highest purity grade. Stock solutions of all the chemicals were made in distilled water/suitable solvent and the dilutions were made fresh on the day of experiment.

Animals

Experiments performed complied with the rulings of the Institute of Laboratory Animal Resources, Commission on Life Sciences, National Research Council [18] and approved by the Ethical Committee of Aga Khan University Karachi. Local male rabbits $(1-1.5 \mathrm{~kg})$ used in the study were bred and housed at the Animal house of Aga Khan University under controlled environment $\left(23-25^{\circ} \mathrm{C}\right)$. Animals were given tap water ad libitum and a standard diet.

The bovine hearts were collected from freshly slaughter animal in normal Krebs solution and coronary vessel was excised out and trimmed from the extravascular tissues in the laboratory.

\section{Isolated tissue preparations}

\section{Langendorrf's perfused isolated rabbit heart}

As described previously $[19,20]$ male healthy rabbits $(1-1.5 \mathrm{~kg}$ ) were injected (i.p) heparin (5000 IU) $1 \mathrm{~h}$ prior of cervical dislocation and isolation of the heart. The thorax was opened by an incision and the heart was removed immediately. The pericardium and other adjacent tissues were removed quickly and aorta was cut at the point of bifurcation, so that about $1 \mathrm{~cm}$ of aorta remained intact. The isolated heart was immediately placed in a petri dish containing the Krebs-Henseleit buffer at $37^{\circ} \mathrm{C}$ and aerated with $5 \% \mathrm{CO}_{2}$ in $\mathrm{O}_{2}$ (carbogen). The composition of KrebsHenseleit buffer was (in $\mathrm{mM}$ ): $118 \mathrm{NaCl}, 4.7 \mathrm{KCl}, 1.2$ $\mathrm{MgSO}_{4} \cdot 7 \mathrm{H}_{2} \mathrm{O}, 1.25 \mathrm{CaCl}_{2}, 24 \mathrm{NaHCO}_{3}, 1.1 \mathrm{KH}_{2} \mathrm{PO}_{4}$ and 10 glucose with $\mathrm{pH} 7.4$.

After gentle squeezing, the heart was attached to the cannula of Langendorrf's apparatus through aorta. The aerated and thermostatically maintained perfusion fluid is allowed to flow into the heart through aorta. A thread is attached through a clip to the apex of the heart and passed 
over a freely moving pulley; another end of the thread was attached to the lever of the isotonic BioScience transducer, which was connected through the amplifier to the oscillograph.

\section{Protocol}

Following cannulation, the retrograde perfusion through the aorta was allowed. Once the heart was mounted on the experimental station, perfusion pressure was adjusted to achieve the satisfactory spontaneous heart beat. Usually 10-15 min was sufficient to attain the steady state. Initially, the normal rhythmic and synchronous cardiac activity and the coronary flow (CF) were observed and recorded, which served as control. All the parameters were observed for another $20 \mathrm{~min}$ before employing the test sample.

Not more than one full dose-response curve was determined on one preparation. Any heart which shown abnormal pattern of the activity was discarded. In some experiments L-NAME $(0.01 \mathrm{mM})$ and indomethacin $(0.01 \mathrm{mM})$ were added to the buffer to avoid the influence of prostaglandin $\mathrm{I}_{2}\left(\mathrm{PGI}_{2}\right)$ and nitric oxide $(\mathrm{NO})$ on the effect of test substances. All these antagonists were used to avoid complications in data interpretation [21].

\section{Dose cycle}

After a control period, different doses of the crude extract of Acorus calamus and its fractions $(\mathrm{mg} / \mathrm{mL})$ and standard drugs were injected gently into the rubber tubing attached to the cannula at the interval of 5-10 min. Measurements were performed both in the controls and in the test. The maximal effect is taken into account during 10 min time following the administration of each dose of test sample(s). Rate of the ventricular contractions, as heart rate (HR) was measured from number of beats per min. Force of ventricular contractions (FVC) was calculated in centimeter from the baseline. CF was calculated from the total number of drops per min, as described previously [19, 20].

\section{Bovine coronary artery}

The protocol of Campbell et al. [22] was followed with some modifications. Bovine hearts were purchased from a local slaughterhouse, and sections of the left anterior descending coronary artery were dissected and cleaned of connective tissue. The artery was cut into 2-mm-diameter rings. Arterial rings were equilibrated in normal Krebs buffer consisting of (in mM) $119 \mathrm{NaCl}, 4.8 \mathrm{KCl}, 2.4$ $\mathrm{NaHCO}_{3}, 3.8 \mathrm{CaCl}_{2}, 1.2 \mathrm{KH}_{2} \mathrm{PO}_{4}, 1.2 \mathrm{MgSO}_{4}, 11$ glucose and 0.02 EDTA at $37^{\circ} \mathrm{C}$, aerated with carbogen and equilibrated for $1.5 \mathrm{~h}$. $\mathrm{KCl}(40 \mathrm{mM})$ was added to the chamber until reproducible maximal contractions were maintained. U46619 (20 nM) was used to induce sustained contraction.

\section{Experimental protocol}

The integrity of endothelium was confirmed by relaxation to bradykinin $(1 \mu \mathrm{M})$. In some vessels, the endothelium was deliberately removed by gently rubbing the lumen with forceps and the success of procedure was confirmed by the inability of bradykinin to induce vasodilatation [22]. The rings were suspended on a pair of stainless steel hooks in a $5 \mathrm{~mL}$ organ chamber. One hook was anchored to a steel rod, and the other was attached to a force transducer (Fort100, WPI, UK). Vessels were equilibrated for $1.5 \mathrm{~h}$ under $2 \mathrm{~g}$ of resting tension. $\mathrm{KCl}(40 \mathrm{mM})$ was added until reproducible contractions were obtained. The thromboxane mimetic, U46619 (20 nM) was then administered to induce sustained contraction. Cumulative additions of the test materials along with standards, such as methacholine and arachidonic acid, were made. To establish the mechanisms of relaxation, some vessels were treated with TEA $(1 \mu \mathrm{M})$, SKF525A $(10 \mu \mathrm{M})$, glibenclamide $(1 \mu \mathrm{M})$, indomethacin $(1 \mu \mathrm{M})$ or vehicle, and the concentration-response curve was determined. Similar experiments were performed with $\left[\mathrm{K}^{+}\right]$in the Krebs solution reduced to $0 \mathrm{mM}$ or increased to 4.8-20 mM. Equivalent changes in $\left[\mathrm{Na}^{+}\right]$were made to maintain isotonicity. Results were expressed as percent relaxation, with $100 \%$ relaxation representing the basal pre-U46619 tension. Changes in isometric tension were recorded and analyzed through a force transducer (Fort100, WPI, UK), coupled with bridge amplifier (Transbridge TBM4) and PowerLab (ML845) data acquisition system (ADInstruments, Sydney, Australia).

\section{Effect on high $\mathrm{K}^{+}$induced contractions in bovine coronary arterial preparations}

To assess the inhibitory effect of Acorus calamus extract on $\mathrm{Ca}^{2+}$ movement through voltage dependent $\mathrm{Ca}^{2+}$ channels, $\mathrm{K}^{+}$, as $\mathrm{KCl}$, was used which produced sustained contractions by depolarization of the preparations [23]. The Acorus calamus extract and its fractions were used in a cumulative fashion, to obtain concentration-dependent inhibitory responses. The relaxation of $\mathrm{K}^{+}(40 \mathrm{mM})$ precontraction was expressed as percent of the control response. Changes in isometric tension were recorded and analyzed through a force transducer (Fort-100, WPI, UK), coupled with bridge amplifier (Transbridge TBM4) and PowerLab (ML845) data acquisition system (ADInstruments, Sydney, Australia). 
Statistics

All the data expressed are mean \pm standard error of the mean (SEM), and the median effective concentrations (EC $\mathrm{EC}_{50}$ values) are given with $95 \%$ confidence intervals (CI). The statistical parameter applied is the student $t$ test with $P<0.05$ noted as significantly different (GraphPad program, GraphPad, San Diego, CA, USA), concentration response curves were analyzed by non-linear regression (GraphPad program).

\section{Results}

\section{Langendorrf's experiments}

In isolated perfused rabbit heart the effect of Ac.Cr and its fractions were observed on three different parameters, such as, force of ventricular contraction (FVC), HR and CF. When tested, Ac.Cr partially (55-60\%) suppressed HR, FVC and $\mathrm{CF}$, with respective $\mathrm{EC}_{50}$ values of 0.13 (0.07-0.24), 0.11 (0.06-0.19) and $1.10 \mathrm{mg} / \mathrm{mL}(0.52-1.80)$, as shown in Fig. 1a. The suppressant effect of Ac.Cr on CF was weak as compared to its effect on HR and FVC.

The Ac.nHexane completely suppressed FVC, partially suppressed $\mathrm{HR}$, with respective $\mathrm{EC}_{50}$ values of 0.17
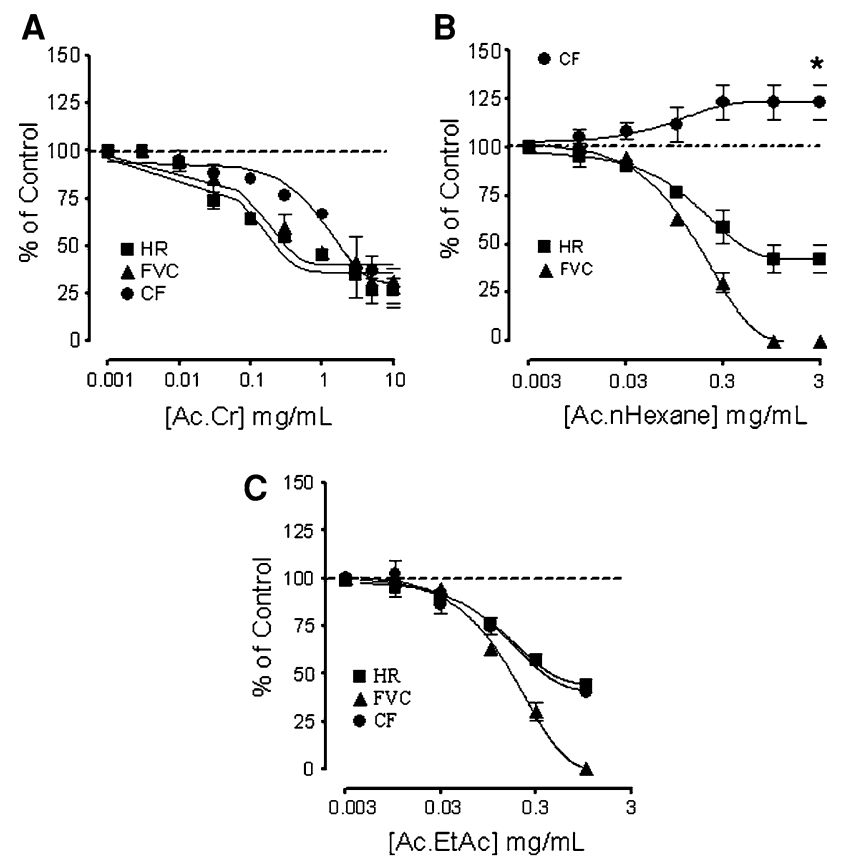

Fig. 1 Effect of a the crude extract of Acorus calamus (Ac.Cr) and its fractions; b $n$ Hexane (Ac. $n$ Hexane) and $\mathbf{c}$ ethylacetate (Ac.EtAc) on the heart rate (HR), force of ventricular contraction (FVC) and coronary flow $(\mathrm{CF})$ in isolated rabbit heart preparations in Langendorrf's experiment. $* P>0.05$ versus base line. Values shown are mean $\pm \operatorname{SEM}(n=3-4)$
(0.13-0.22) and $0.82 \mathrm{mg} / \mathrm{mL}(0.43-1.55)$ while caused modest increase in $\mathrm{CF}$ (Fig. 1b). Ac.EtAc completely suppressed FVC and partially inhibited both $\mathrm{HR}$ and $\mathrm{CF}$, with respective $\mathrm{EC}_{50}$ values of 0.17 (0.13-0.23), 0.70 (0.49-1.0) and $0.54 \mathrm{mg} / \mathrm{mL}(0.33-0.87)$ as shown in Fig. 1c.

Methacholine partially inhibited FVC, completely suppressed HR while caused a modest increase in CF (Fig. 2a). Arachidonic acid exhibited weak inhibitory effect on FVC, no effect on HR, while caused a dominant increase in $\mathrm{CF}$, which was about $80 \%$ of the control (Fig. 2b). Verapamil caused complete suppression of FVC, HR and CF (Fig. 2c).

Effect on bovine coronary artery

The bovine coronary vessels that were pre-contracted with U46619 (20 nM) produced endothelium-dependent relaxation to Ac.Cr, with $\mathrm{EC}_{50}$ value of $2.5 \mathrm{mg} / \mathrm{mL}$ (1.8-3.11). The relaxation was inhibited in vascular ring preparations without functional endothelium (denuded) and in the presence of increasing concentrations (4.8 and $20 \mathrm{mM}$ ) of $\mathrm{K}^{+}$in the buffer (Fig. 3a); similar effects were observed with methacholine (Fig. 4a) and arachidonic acid (Fig. 4c). Pretreatment of the arterial rings with TEA $(1 \mu \mathrm{M})$ and SKF525A $(10 \mu \mathrm{M})$, did not alter basal tension or contractions to U46619, however, inhibited the relaxations to
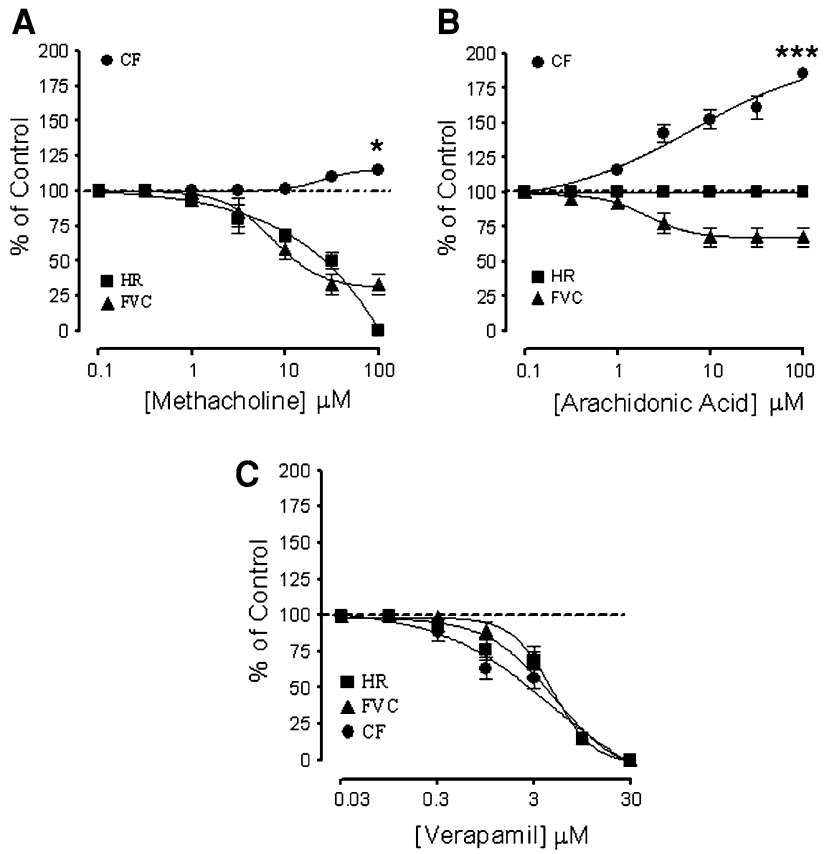

Fig. 2 Effect of a methacholine, $\mathbf{b}$ arachidonic acid and $\mathbf{c}$ verapamil on the heart rate (HR), force of ventricular contraction (FVC) and coronary flow (CF) in isolated rabbit heart preparations in Langendorrf's experiment. $* P>0.05$ versus base line; $* * * P>0.0001$ versus base line. Value shown are the mean $\pm \operatorname{SEM}(n=4)$ 

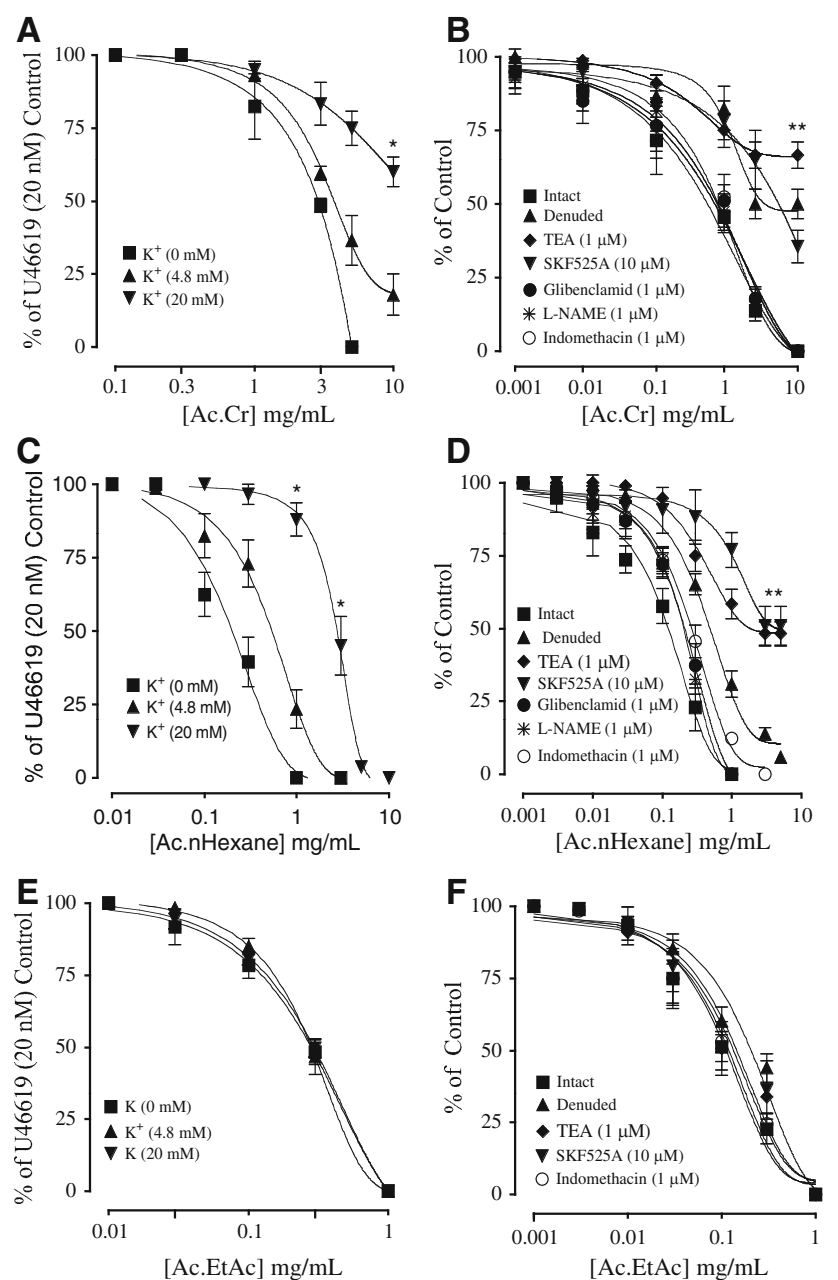

Fig. 3 Isolated bovine left descending coronary arterial rings with intact and denuded endothelium were constricted with U46619 $(20 \mathrm{nM})$ and cumulative effect of the crude extract of Acorus calamus (Ac.Cr) and its fractions was determined. a, c, and e depict, respectively, the effect of Ac.Cr and its $n$ Hexane (Ac. $n$ Hexane) and ethylacetate (Ac.EtAc) fractions in presence of varying concentrations ( 4.8 and $20 \mathrm{mM}$ ) of $\mathrm{K}^{+}$, in the Kreb's solution. $\mathbf{b}, \mathbf{d}$, and $\mathbf{f}$ show, respectively, the effect of Ac.Cr, Ac.nHexane and Ac.EtAc in the intact arterial rings in the absence and presence of TEA $(1 \mu \mathrm{M})$, SKF525A $(10 \mu \mathrm{M})$, glibenclamide $(1 \mu \mathrm{M})$ and L-NAME $(1 \mu \mathrm{M})$ and in the denuded rings preparations. $* P>0.05$ versus base line; $* * P>0.001$ versus base line. Value shown are mean \pm SEM $(n=5-10)$

Ac.Cr (Fig. 3b), similar to methacholine (Fig. 4b) and arachidonic acid (Fig. 4d). The relaxant effect of Ac.Cr remained unchanged in arterial rings pretreated with glibenclamide $(1 \mu \mathrm{M})$, L-NAME $(1 \mu \mathrm{M})$ and indomethacin $(1 \mu \mathrm{M})$.

Ac.nHexane also caused relaxation of U46619-induced vasoconstrictions in a concentration-related manner, with $\mathrm{EC}_{50}$ value of $0.21 \mathrm{mg} / \mathrm{mL}(0.17-0.29)$. The relaxation to Ac. $n$ Hexane was inhibited in the presence of increasing concentrations ( 4.8 and $20 \mathrm{mM})$ of $\mathrm{K}^{+}$in the buffer (Fig. 3c) and rings pretreated with TEA $(1 \mu \mathrm{M})$ and
A

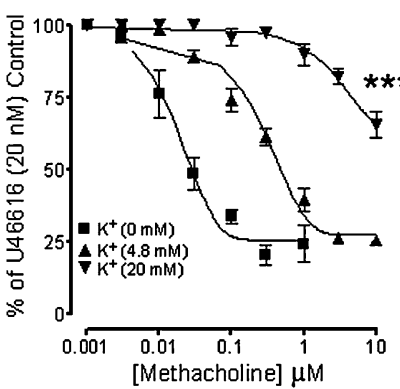

C

B
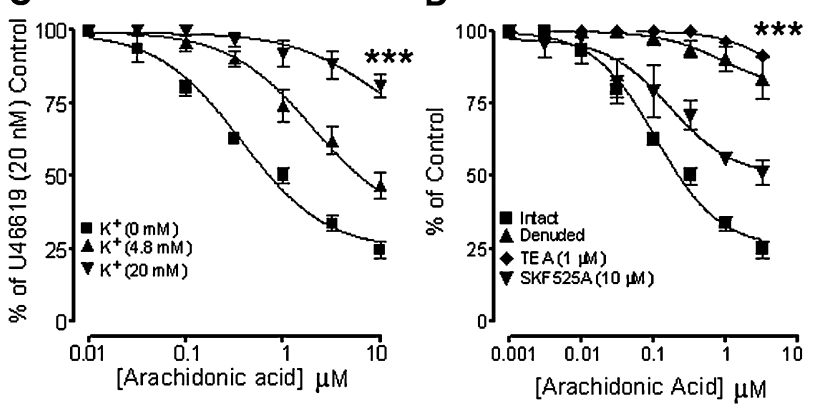

Fig. 4 Isolated bovine left descending coronary arteries were constricted with U46619 (20 nM) and cumulative effect of methacholine and arachidonic acid was determined in intact and denuded endothelium rings. a and $\mathbf{c}$ depict the effect of methacholine and arachidonic, respectively, in the arterial rings in presence of varying concentrations (4.8 and $20 \mathrm{mM}$ ) of $\mathrm{K}^{+}$in the Krebs' solution. b and d show, respectively, the effect of methacholine and arachidonic acid in denuded and in intact arterial rings preparations in the absence and presence of TEA $(1 \mu \mathrm{M})$ and SKF525A $(10 \mu \mathrm{M})$. $* * * P>0.0001$ versus base line. Values shown are mean $\pm \operatorname{SEM}(n=8-14)$

SKF525A (10 $\mu \mathrm{M})$ (Fig. 3d) and remained unchanged in rings pretreated with glibenclamide $(1 \mu \mathrm{M})$, L-NAME $(1 \mu \mathrm{M})$ and indomethacin $(1 \mu \mathrm{M})$.

Ac.EtAc also produced relaxation to U46619induced vasoconstrictions in a concentration-related manner but the effect remained unchanged in presence of increasing concentrations of $\mathrm{K}^{+}(4.8$ and $20 \mathrm{mM})$ in the buffer (Fig. 3e) and in rings pretreated with $\operatorname{TEA}(1 \mu \mathrm{M}), \quad \operatorname{SKF} 525 \mathrm{~A}(10 \mu \mathrm{M})$ and indomethacin $(1 \mu \mathrm{M})$ (Fig. 3f).

Effect on high $\mathrm{K}^{+}$precontractions in bovine coronary artery

In isolated bovine coronary arterial rings, cumulative addition of crude extract of Acorus calamus caused inhibition of the high $\mathrm{K}^{+}(20 \mathrm{mM})$ precontractions with $\mathrm{EC}_{50}$ value of $0.34 \mathrm{mg} / \mathrm{mL}(0.28-0.49)$ (Fig. 5). Among the tested fractions, the ethylacetate fraction was more potent than the parent crude extract and $n$ Hexane fraction, with respective $\mathrm{EC}_{50}$ values of $0.06(0.04-0.08)$ and $0.98 \mathrm{mg} / \mathrm{mL}$ (0.64-1.48) (Fig. 5). 


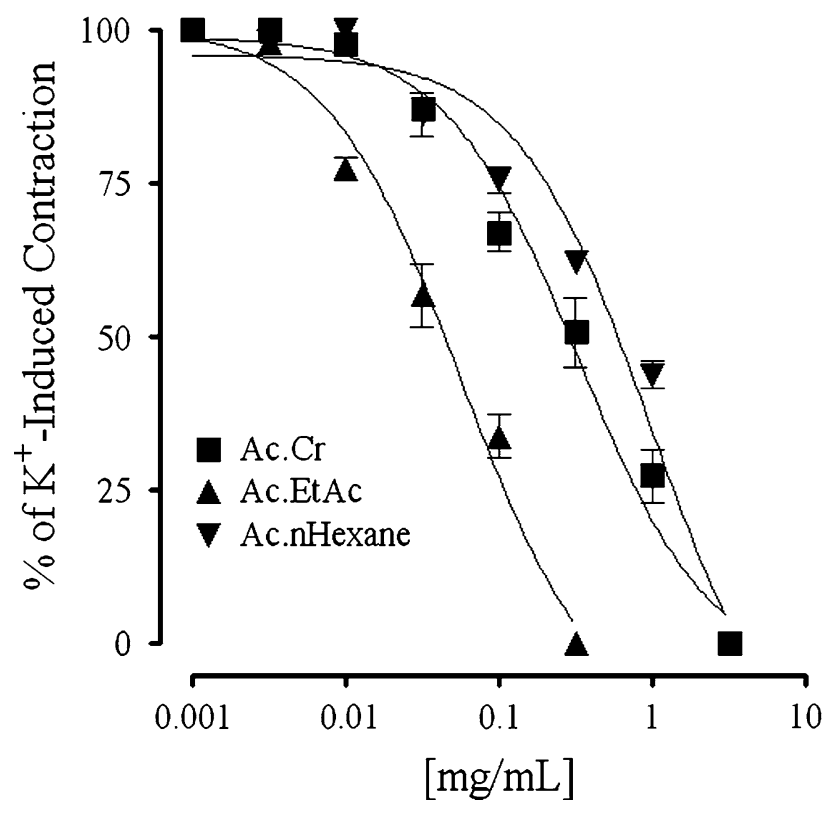

Fig. 5 Effect of the crude extract of Acorus calamus (Ac.Cr) and its ethylacetate (Ac.EtAc) and $n$ Hexane (Ac. $n$ Hexane) fractions on high $\mathrm{K}^{+}(20 \mathrm{mM})$-induced contractions in isolated bovine left descending coronary arterial preparations. Values shown are mean \pm SEM $(n=10-16)$

\section{Discussion}

As an extension of a previous study [14], the crude extract and fractions of Acorus calamus were further studied based on its medicinal use in ischemic heart diseases [3]. Langendorrf's perfused rabbit heart and isolated bovine coronary arterial preparations were used. The aim here was to study the functional nature of the pharmacological effect of Ac.Cr and its fractions on $\mathrm{CF}$, as mediated through EDHF, in addition to their effect on FVC and HR. The effect of other mediators of endothelial origin, such as, NO and $\mathrm{PGI}_{2}$ were ruled out by the addition of L-NAME, a NO synthase inhibitor [24] and indomethacin, a $\mathrm{PGI}_{2}$ inhibitor [25] to the Krebs-Henseleit solution. Under these experimental conditions, Ac.Cr caused partial $(\geq 60 \%)$ inhibition of FVC, HR and, CF. Verapamil, a standard calcium channel blocker [26], caused complete suppression. Ac.EtAc completely suppressed FVC and partially inhibited HR and CF. The $n$ Hexane fraction unlike the crude extract suppressed FVC, partially inhibited HR while caused modest increase in CF, similar to methacholine and or arachidonic acid. The complete or partial suppression of the cardiac parameters by the crude extract and its fractions may involve inhibitory effect on calcium channels.

When tested in isolated bovine coronary arterial ring preparations pre-contracted with high $\mathrm{K}^{+}(20 \mathrm{mM})$, the ethylacetate fraction was found to be more potent than the parent crude extract and the $n$ Hexane fraction thus suggesting that the possible presence of $\mathrm{Ca}^{2+}$ channel blocking component observed in terms of inhibitory effect against high $\mathrm{K}^{+}$[27], as reported in the previous study [14] is concentrated in the ethylacetate fraction. Calcium channel blockers, such as verapamil are known to possess negative inotropic and chronotropic effects [28, 29] and depress $\mathrm{CF}$ in isolated heart preparations, where $\mathrm{CF}$ is largely dependent on myocardial contractility [30], so the direct effect of such drugs on $\mathrm{CF}$ is not evident [31]. The partial inhibitory effect of the crude extract on cardiac parameters might be of potential clinical advantage, as complete inhibitory effect, like that of verapamil, can lead to myocardial suppression, as a side effect.

The functional nature of the effect on $\mathrm{CF}$ was further studied in isolated bovine coronary arterial preparation. The endothelium has emerged as an important regulator of vascular tone. Several soluble mediators released by the endothelium are involved in these vascular effects, such as prostacyclin, NO and EDHF. The EDHF release hyperpolarizes the underlying smooth muscle cells by activation of $\mathrm{K}^{+}$channels, the most frequent being $\mathrm{K}_{\mathrm{Ca}}$ channels [32]. The activity of EDHF may be distinguished from NO; EDHF activity is blocked by TEA, inhibitors of $\mathrm{K}_{\mathrm{Ca}}$ [21], or by high $\mathrm{K}^{+}$but not by L-NAME or glibenclamide, inhibitor of $\mathrm{K}_{\text {ATP }}$ channel [33].

When tested on the U46619, thromboxane prostanoid receptors activator [34], precontractions in bovine coronary arterial preparations with intact endothelium, Ac.Cr exhibited downstream effect, which was inhibited in presence of increasing concentrations of $\mathrm{K}^{+}$in the buffer, similar to methacholine and arachidonic acid. Potassium causes vasodilatation at low concentrations $(<14 \mathrm{mM})$ through hyperpolarization and activation of $\mathrm{Na}^{+}-\mathrm{K}^{+}$ ATPase [34]. At higher $(>14 \mathrm{mM})$ concentrations $\mathrm{K}^{+}$ cause depolarization and contraction of the smooth muscle because potassium at high concentration inactivates all $\mathrm{K}^{+}$ channels [35] and allows voltage-gated calcium channels to open [27]. Thus $\mathrm{K}^{+}$functions as an EDHF within the concentration window of $4.8-14 \mathrm{mM}[34,36]$. The inhibition of the relaxant effect of Ac.Cr in the presence of increasing concentration of $\mathrm{K}^{+}$, suggests that Ac.Cr mediates the downstream effect through activation of $\mathrm{K}_{\mathrm{Ca}}$ and may act as EDHF. This hypothesis was further confirmed when the induced relaxation of crude extract was blocked in presence of TEA and remained unchanged in the presence of glibenclamide and L-NAME, excluding the involvement of $\mathrm{K}_{\mathrm{ATP}}$ channels or NO.

Methacholine, a known EDHF releasing agent [37], is also known to stimulate the release of several arachidonic acid metabolites which further causes relaxation and hyperpolarization, the effect is sensitive to inhibitors of cytochrome $\mathrm{P}_{450}$, such as, SKF525A [21]. Interestingly, the downstream effect of Ac.Cr was also attenuated when 
repeated in the presence of SKF525A. This indicates that Ac.Cr caused the EDHF-mediated downstream effect possibly via the release of arachidonic acid metabolites, similar to methacholine. Arachidonic acid, in coronary endothelial cells, is known to metabolize by cytochrome $\mathrm{P}_{450}$ activity to epoxyeicosatrienoic acids (EETs) [38]. Studies from a number of laboratories indicate that EETs function as an EDHF [39]. The EDHF mediated hyperpolarization and subsequent vascular relaxation is uninfluenced in the presence of L-NAME, NO synthase inhibitor or indomethacin, a cyclooxygenase inhibitor. However, the relaxation induced by arachidonic acid is blocked by inhibitors of cytochrome $\mathrm{P}_{450}$ [38], as well as TEA and high $\mathrm{K}^{+}$. When tested in another set of experiment, the downstream effect of Ac.Cr remained unchanged in the presence of L-NAME and indomethacin, suggesting the release of EDHF from the endothelial cells, similar to that observed with methacholine and arachidonic acid.

Ac. $n$ Hexane caused an endothelium-dependent downstream effect against U46619-induced contractions in coronary arteries, which was attenuated in the presence of high $\mathrm{K}^{+}$, TEA and SKF525A, similar to that observed with methacholine and arachidonic acid. The Ac. $n$ Hexane was about ten times more potent in inhibiting U46619-induced contractions than the parent crude extract, which indicate that the EDHF-mediated relaxant activity is concentrated in this particular fraction.

Interestingly, the ethylacetate fraction caused inhibition of the U46619-induced contractions but the effect remained unchanged in the presence of high $\mathrm{K}^{+}$, TEA, SKF525A or indomethacin. This suggests that this effect may be due to the presence of calcium channel blocking (CCB) constituent in the extract of Acorus calamus, because the ethylacetate fraction was more potent in inhibiting high $\mathrm{K}^{+}$precontraction in isolated bovine coronary arterial rings than the crude extract and $n$ Hexane fraction.

Endothelium-dependent relaxation and hyperpolarization mechanism is impaired in ischemic heart diseases [40] and different $\mathrm{K}^{+}$channels have been identified in myocardial cells [41] where their activation may function as a downstream mechanism in ischemic preconditioning and reduction in myocardial ischemic injury [32]. Endothelium-dependent hyperpolarization and subsequent vascular relaxation are inhibited by blockers of $\mathrm{K}_{\mathrm{Ca}}$ channels in coronary arteries [42], suggesting that the activation of $\mathrm{K}_{\mathrm{Ca}}$ channels plays an important role in coronary vasodilatation [43]. Thus, the vascular relaxant effect of the crude extract and its $n$ Hexane fraction in coronary artery, which is supposed to be mediated via the release of EDHF, strongly support and provides pharmacological rationale to the medicinal use of Acorus calamus in ischemic heart diseases, though further chemical isolation and molecular characterization, would provide more insight into the effect.

In conclusion, these data indicate that the crude extract of Acorus calamus possesses coronary vasodilator effect, mediated possibly through EDHF. The partial cardiac depressant effect may be of added value as complete suppression may lead to cardiac arrest. This study provides pharmacological rationale, with respect to the medicinal use of Acorus calamus in ischemic heart diseases.

Acknowledgments This study was carried out with partial support from the Pakistan Science Foundation. The authors are thankful to Mr. Stephen Hudson, Department of Biochemistry, Medical College of Wisconsin, USA, for the grammatical and typographical corrections in the manuscript.

\section{References}

1. Wiart C (2002) Medicinal plants of South East Asia. Prentice Hall, Selangor

2. Wallis TE (1985) Text book of pharmacognosy. CBS Publishers \& Distributors, New Delhi

3. Duke JA, Bogenschutz-Godwin MJ, Du celliar J, Duke PK (2002) Hand book of medicinal herbs, 2nd edn. CRC Press, Boca Raton

4. Baquar SR (1989) Medicinal and poisonous plants of Pakistan. Printas, Karachi

5. Kapoor LD (2000) Handbook of Ayurvedic medicinal plants. CRC Press, Boca Raton

6. Danilevskii NF, Antonishin BV (1982) Antimicrobial activity of a tincture of Japanese pagoda tree (Sophora japonica) and of the essential oil of sweet flag (Acorus calamus). Mikrobiol $\mathrm{Zh}$ 44:80-82

7. Shoba FG, Thomas M (2001) Study of antidiarrhoeal activity of four medicinal plants in castor-oil induced diarrhoea. J Ethnopharmacol 76:73-76

8. Parab RS, Mengi SA (2002) Hypolipidemic activity of Acorus calamus L. in rats. Fitoterapia 73:451-455

9. Shukla PK, Khanna VK, Ali MM, Maurya RR, Handa SS, Srimal RC (2002) Protective effect of Acorus calamus against acrylamide induced neurotoxicity. Phytother Res 16:256-260

10. Acuna UM, Atha DE, Ma J, Nee MH, Kennelly EJ (2002) Antioxidant capacities of ten edible North American plants. Phytother Res 16:63-65

11. Oh MH, Houghton PJ, Whang WK, Cho JH (2004) Screening of Korean herbal medicines used to improve cognitive function for anti-cholinesterase activity. Phytomedicine 11:544-548

12. Jain N, Jain R, Jain A, Jain DK, Chandel HS (2010) Evaluation of wound-healing activity of Acorus calamus Linn. Nat Prod Res 24:534-541

13. Gilani AH, Shah AJ, Manzoor A, Farzana S (2006) Antispasmodic effect of Acorus calamus Linn. is mediated through calcium channel blockade. Phytother Res 20:1080-1084

14. Shah AJ, Gilani AH (2009) Blood pressure lowering and vascular modulator effects of Acorus calamus extract are mediated through multiple pathways. J Cardiovasc Pharmacol 54:38-46

15. Williamson EM, Okpako DT, Evans FJ (1998) Pharmacological methods in phytotherapy research. Wiley, Chichester

16. Venkatesh S, Madhava RB, Dayanand RG, Mullangi R, Lakshman M (2010) Antihyperglycemic and hypolipidemic effects of Helicteres isora roots in alloxan-induced diabetic rats: a possible mechanism of action. J Nat Med 64:295-304 
17. Wang Y, Han T, Zhu Y, Zheng CJ, Ming QL, Rahman K, Qin LP (2010) Antidepressant properties of bioactive fractions from the extract of Crocus sativus L. J Nat Med 64:24-30

18. National Research Council (1996) Guide for the care and use of laboratory animals. National Academy Press, Washington

19. Balderston SM, Johnson KE, Reiter MJ (1991) Electrophysiologic evaluation of cardiovascular agents in the isolated intact rabbit heart. J Pharmacol Methods 25:205-213

20. Taqvi SIH, Ghayur MN, Gialni AH, Saify ZS, Aftab MT (2006) Synthesis and smooth muscle-selective relaxant activity of a piperidine analogue: 1-(4'-fluorophenacyl)-4-hydroxy-4-phenylpiperidinium chloride. Arch Pharm Res 29:34-39

21. Stephen F, Malcolm JL (1993) A factor released from coronary vascular endothelium inhibits myocardial contractile performance. Am J Physiol Heart Circ Physiol 264:H830-H836

22. Campbell WB, Gebremedhin D, Pratt PF, Harder DR (1996) Identification of epoxyeicosatrienoic acids as endotheliumderived hyperpolarizing factors. Circ Res 78:415-423

23. Farre AJ, Columbo M, Fort M, Gutierrez B (1991) Differential effects of various $\mathrm{Ca}^{2+}$ antagonists. Gen Pharmacol 22:177-181

24. Fantel AG, Nekahi N, Shepard TH, Cornel LM, Unis AS, Lemire RG (1997) The teratogenicity of $N^{\mathrm{G}}$-nitro-L-arginine methyl ester (L-NAME), a nitric oxide synthase inhibitor in rats. Reprod Toxicol 11:709-717

25. Moncada S, Korbut R, Bunting S, Vane JR (1978) Prostacyclin is a circulating hormone. Nature 273:767-768

26. Fleckenstein A (1977) Specific pharmacology of $\mathrm{Ca}^{2+}$ in myocardium, cardiac pacemakers and vascular smooth muscle. Rev Pharmacol Toxicol 17:149-166

27. Bolton TB (1979) Mechanism of action of transmitters and other substances on smooth muscles. Physiol Rev 59:606-718

28. Rang HP, Dale MM, Ritter JM (1995) Pharmacology. Churchill Livingstone, London

29. Feigl EO (1983) Coronary physiology. Physiol Rev 63:1-205

30. Bova S, Cargnelli G, D'Amato E, Forti S, Yang Q, Trevisi L, Debetto P, Cima L, Luciani S, Padrini R (1997) Calcium-antagonist effects of norbormide on isolated perfused heart and cardiac myocytes of guinea-pig: a comparison with verapamil. $\mathrm{Br} \mathrm{J}$ Pharmacol 120:19-24

31. Feletou M, Vanhoutte PM (1988) Endothelium-dependent hyperpolarization of canine coronary smooth muscle. Br J Pharmacol 93:515-524

32. Qian YZ, Levasseur JE, Toshida KI, Kukreja RC (1996) $\mathrm{K}_{\text {ATP }}$ channels in rat heart: blockade of ischemic and acetylcholine- mediated preconditioning by glibenclamide. Am J Physiol 271:H23-H28

33. Huang JS, Ramamurthy SK, Lin X, Le BGC (2004) Cell signaling through thromboxane A2 receptors. Cell Signal 16:521-533

34. Edwards G, Dora KA, Gardener MJ, Garland CJ, Weston AH (1998) $\mathrm{K} 1$ is an endothelium-derived hyperpolarizing factor in rat arteries. Nature 396:269-272

35. Ross GR, Yallampalli C (2006) Endothelium-independent relaxation by adrenomedullin in pregnant rat mesenteric artery: role of cAMP-dependent protein kinase A and calcium-activated potassium channels. JPET 317:1269-1275

36. Dora KA, Garland CJ (2001) Properties of smooth muscle hyperpolarization and relaxation to potassium in the rat isolated mesenteric artery. Am J Physiol Heart Circ Physiol 280:H2424$\mathrm{H} 2429$

37. Silvia N, Wiliam SW, Hilary L, Andrea L, Susan M, Andrew GP, Wiliam M (2003) Evaluation of potassium ion as the endothelium-derived hyperpolarizing factor (EDHF) in the bovine coronary artery. Br J Pharmacol 139:982-988

38. Rosolowsky M, Campbell WB (1993) Role of PGI2 and EETs in the relaxation of bovine coronary arteries to arachidonic acid. Am J Physiol 264:H327-H335

39. Gebremedhin D, Harder DR, Pratt PF, Campbell WB (1998) Bioassay of an endothelium-derived hyperpolarizing factor from bovine coronary arteries: role of a cytochrome P450 metabolite. J Vasc Res 35:274-284

40. Fujii K, Tominaga M, Ohmori S, Kobayashi K, Koga T, Takata Y, Fumjishima M (1992) Decreased endothelium-dependent hyperpolarization to acetylcholine in smooth muscle of the mesenteric artery of spontaneously hypertensive rats. Circ Res 70:660-669

41. Trautwein W (1973) Membrane currents in cardiac muscle fibres. Physiol Rev 53:793-835

42. Holzmann S, Kukovetz WR, Windischhofer W, Paschke E, Graier WF (1994) Pharmacologic differentiation between endothelium-dependent relaxations sensitive and resistant to nitroL-arginine in coronary arteries. J Cardiovasc Pharmacol 23:747-756

43. Cohen RA, Vanhoutte PM (1995) Endothelium-dependent hyperpolarization-beyond nitric oxide and cyclic GMP. Circulation 92:3337-3349 